\title{
Chapter 4 \\ Biological Invasions: A Case Study of Baltic Sea Environmental Governance
}

\author{
Katarzyna Smolarz, Paulina Biskup, and Aleksandra Zgrundo
}

\begin{abstract}
This chapter describes bioinvasions as an example of a relatively new crosscutting domain of environmental governance whose management is affected by a high level of uncertainty, complexity and ambiguity. In the Baltic Sea region, legislation and policies related to invasive alien species (IAS) are still under development, and as a consequence, there are a few legally binding instruments dealing with the problem. Due to the fact that environmental changes linked to other environmental risks (eutrophication, maritime transportation, climate change) may intensify biological incursions, development of a uniform policy, followed by its ratification among EU Member States in the Baltic Sea region as well as Russia, is generally seen as a top priority for many actors involved in environmental governance. Hence, the adoption of a precautionary approach and the Ecosystem Approach to Management (EAM) driven by precise goals and executed by policies and best practices are proposed as holistic and necessary management tools for preventing and controlling bioinvasions. This chapter focuses on barriers and opportunities for the implementation of the EAM concept and on identifying possible ways to improve the effectiveness of IAS management. Finally, we argue that biological invasions and in particular their consequences may impact on a wide set of ecosystem goods and services, and therefore, holistic management that takes into account interdependencies among environmental issues is required.
\end{abstract}

Keywords Baltic Sea • Invasive alien species (IAS) • Ballast water management • Ecosystem approach to management $\bullet$ Maritime transportation

K. Smolarz $(\bowtie) \cdot$ P. Biskup • A. Zgrundo

Department of Marine Ecosystem Functioning, Institute of Oceanography, University of

Gdańsk, Al. Marszałka Piłsudskiego 46, 81-378 Gdynia, Poland

e-mail: oceksm@univ.gda.pl; paulina_lemke@wp.pl; oceazg@ug.edu.pl 


\subsection{Introduction}

Although invasive alien species (IAS) can lead to significant negative environmental impacts in the Baltic Sea, environmental risks of such biological invasions have traditionally not attracted as much attention in the Baltic Sea as in other marine areas. In fact, it is only recently that IAS has received significant attention in formal environmental governance arrangements in the EU and the Baltic Sea region.

The assessment and subsequent management of risks and problems associated with biological invasions are fraught with severe challenges of ecological and sociopolitical nature because of uncertainties with regard to the actual impacts of biological invasions and the rather incoherent architecture of European and regional legislation. ${ }^{1}$ Adding to these challenges is also the fact that the biodiversity impacts of IAS can be evaluated as either positive (e.g. introduction of new commercial fish species) or negative (outcompeting of native species) depending on the species and contexts considered. Hence, the high level of uncertainty, complexity and ambiguity linked to IAS risks and impacts, as well as the often significant interrelationships with other environmental issues like eutrophication, overfishing and chemical pollution, may all hinder or delay the development and implementation of relevant legislative acts and management options. It should also be underlined that biological invasions in marine ecosystems often lead to large-scale risks and consequences. This means that the effectiveness of IAS mitigation measures is inherently dependent on cross-border and international cooperation.

This chapter describes and analyses biological invasions as examples of a relatively new and crosscutting domain of environmental governance. The main focus is on identifying and analysing the main barriers and opportunities in the governance of Baltic Sea IAS, as well as on identifying possible ways to achieve environmental governance improvements. The study is based on a 5-year (2009-2014) case study undertaken within the research project 'Environmental Risk Governance of the Baltic Sea' (RISKGOV), where the main emphasis was on alien species (AS) and IAS. The first phase of this study relied on an extensive literature review and database searches, both national and international. The second phase involved discussions and interviews with a number of stakeholders to further explore the issues identified as significant and provide broader input and additional information. Representatives from the following five groups of stakeholders were interviewed (19 interviews in total): officials representing governmental organisations (GOs) (European Commission (EC), HELCOM, national government authorities; five), industry (International Maritime Organisation (IMO), port authorities; three), representatives of non-governmental organisations (NGOs) (global and regional environmental organisations; three), experts from academia (four) along with independent experts and professionals (representatives of various institutions and organisations

\footnotetext{
${ }^{1}$ Commission staff working document. Executive summary of the impact assessment. European Commission, Brussels, 09.09.2013: http://eur-lex.europa.eu/legal-content/EN/TXT/PDF/?uri=CE LEX:52013SC0322\&from=EN
} 
advising on environmental issues; four) from Poland, Sweden, Lithuania, Finland and Belgium. The interviews followed an analytical framework covering the broad topics of the IAS framing (definitions used, IAS impact on the environment and humans, etc.), regulatory frameworks, risk assessment and management, processes of communication, scientific uncertainty and disagreement as well as information relating to the role of the respondents' institutions and their responsibilities. A thematic analysis of data was subsequently performed, where emphasis was placed on qualitative meanings as opposed to quantifying data. Furthermore, these findings were supplemented by participatory observations made during relevant conferences, workshops and meetings.

The chapter is organised as follows: Sect. 4.2 describes the concept of alien species and invasiveness and discusses the consequences of introducing such species in the Baltic Sea region. Section 4.3 discusses uncertainty in risk assessment as the main challenge for IAS management. Section 4.4 presents the main legal frameworks related to bioinvasions. Section 4.5 focuses on the framing and implementation of EAM. Section 4.6 presents conclusions and recommendations pertaining to IAS management.

\subsection{Framing of the Problem}

There are a number of definitions of alien species, invasive species and invasive alien species. If not stated otherwise, within this chapter we concentrate on IAS. The most common definition of IAS is the one proposed by the Convention on Biological Diversity (CBD; COP 6 Decision VI/232), namely, 'alien species whose introduction and spread threatens ecosystems, habitats or species with economic or environmental harm'. The process of IAS invasion is referred to as bioinvasion (or biological invasion). There are several routes to IAS introduction, both natural and man-made, but ballast waters used in maritime transportation are currently seen as the main source of the problem because of the fact that maritime transportation has increased enormously not only worldwide but also in the Baltic Sea region (HELCOM 2009a, b; Olenin et al. 2010). Within the Baltic Sea, despite its relatively small size, ship traffic is one of the densest in the world, both in terms of ship numbers and tonnage. Based on information from the HELCOM AIS (Automatic Identification System) database, more than 50,000 vessels cross the Danish straits per year, and at any time, approximately 2,000 vessels can be found in the Baltic Sea. ${ }^{3}$ Therefore, according to the Directorate-General for Maritime Affairs and Fisheries (DG Mare 2012), the Baltic Sea is one of the sea basins with the greatest environmental pressure due to shipping activities.

Globally, IAS is considered to be one of the greatest threats to marine biodiversity, entailing both direct and indirect consequences for ecosystems with various

\footnotetext{
${ }^{2}$ http://www.cbd.int/decision/cop/?id=7197

${ }^{3} \mathrm{http}: / /$ www.helcom.fi/press_office/news_helcom/en_GB/Ship_traffic_stat/
} 


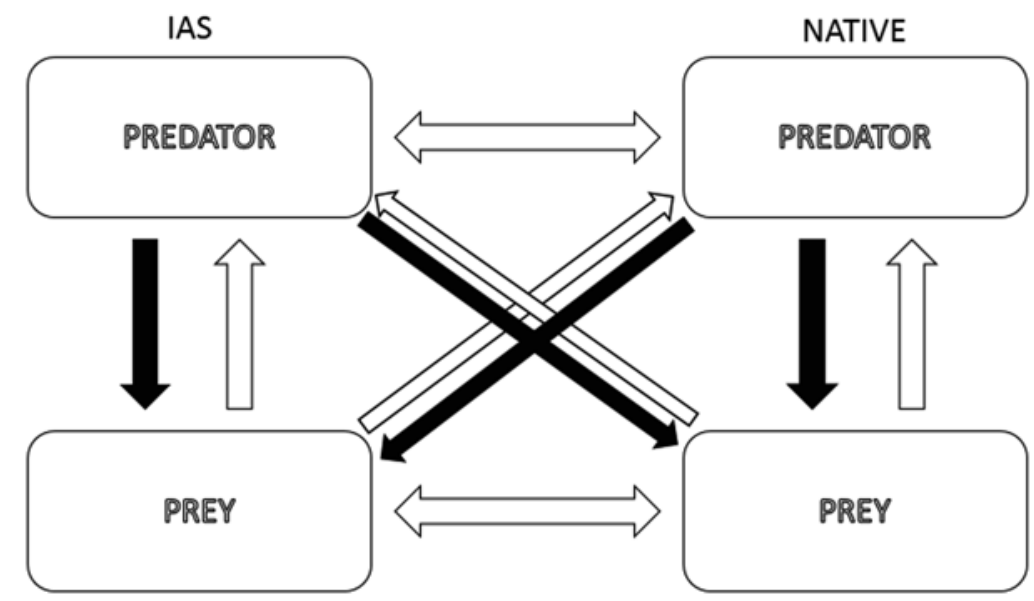

Fig. 4.1 Simplified food-web regulation via three main mechanisms: top-down by population at next trophic level (dark arrows), bottom-up by the presence of organisms they feed on (white arrows) and horizontal, for example, competition (double arrows)

economic and social costs (Born et al. 2005). Zavaleta et al. (2001) describe two basic mechanisms in which food-web interactions can be distorted by IAS introduction, mainly due to the fact that ecosystems usually do not have self-protecting mechanisms against harmful effects of invaders. Identified top-down mechanisms (Fig. 4.1) are linked to the presence of higher level consumers (i.e. grazers or predators) regulating the size of population they feed on, while bottom-up mechanisms regulate the population size of these higher level consumers through the availability of food resources (amount of primary producers or lower level consumers (Zavaleta et al. 2001). The complexity of relations is intensified by the fact that organisms often feed at more than one trophic level. Horizontal mechanisms are mainly linked to competition, for example, for resources, light, physical space and food. However, IAS can affect native species in a number of other ways too, namely, through crossbreeding and the introduction of pathogens. In multiple-invaded ecosystems, therefore, both the horizontal and vertical relationships between different trophic levels become much more complex and uncertain (Bull and Courchamp 2009).

Worldwide IAS-related environmental impacts inflict massive economic costs on fisheries, industry and other human activities (Shine et al. 2010), although the economic evaluation of biological invasions is a difficult task. According to Born et al. (2005), most current studies have methodological shortcomings, mainly due to the fact that they are ex-post impact assessments and insufficiently address uncertainty issues. Furthermore, calculated expenses include mostly direct costs like the damage of harbour infrastructure caused by fouling organisms and usually exclude indirect economic losses such as biodiversity and habitat change, impacts on endemic species and decreasing genetic diversity/identity of local populations. Some introductions, however, can be regarded as beneficial for ecosystems, which adds to the 


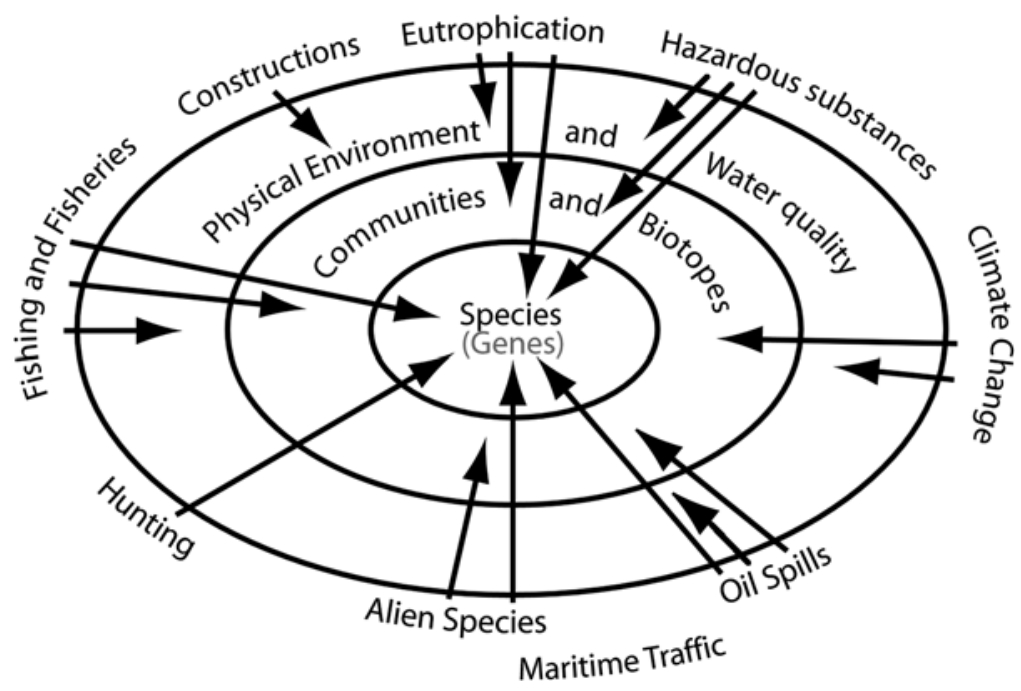

Fig. 4.2 Most important biodiversity threats identified in the Baltic Sea region (Modified from HELCOM 2009c)

complexity of the problem. In such cases, AS (through the processes of primary succession) increase species richness and taxonomic diversity in a given area and increase and strengthen functional diversity and/or provide new services and goods (Bonsdorff 2006; Kotta et al. 2006).

It must be emphasised that the Baltic Sea is 'a sea of aliens' (Leppäkoski et al. 2002), since almost all marine organisms present today invaded the area sometime over the last 10,000 years. However, as it was mentioned previously, the invasion rate has accelerated enormously since the 1950s mainly due to human activities (such as maritime transportation and habitat change). Moreover, synergistic effects of factors such as pollution, eutrophication, overfishing and climate change stimulate new invasions (Fig. 4.2). Changes in environmental conditions and human pressure have on the one hand resulted in the elimination of highly specialised or sensitive native species from the Baltic ecosystem, while on the other hand they have generated and opened niches that have been quickly inhabited by new species. To some extent, the process of bioinvasion can be regarded as positive when species richness and taxonomic diversity are considered. For example, studies on the widespread Baltic invasive polychaete Marenzelleria spp. have shown that although this species has become dominant, it has not adversely affected deeper benthic communities, since it fills an 'empty' niche. However, in shallow waters this has not been the case, and Marenzelleria spp. competes with the native polychaete worm Hediste diversicolor and affects the abundance of the amphipod Monoporeia affinis (Didžiulis 2006; Kotta and Olafsson 2003).

Other positive consequences of alien species introduction include human benefits from both AS and IAS which has actually polarised public perceptions about bioinvasion. For example, Eriocheir sinensis (Chinese mitten crab), a famous 
delicacy in Chinese cuisine, invaded the North Sea in the early twentieth century. It quickly became abundant and established self-sustaining populations in German waters disturbing fishery and aquaculture and, among other things, increasing bank erosion. The monetary impact caused by this invader in German waters alone was estimated at approximately 80 million Euros from its advent locally (Gollasch 2011). Recently, however, particularly in the absence of fish, the mitten crab has been harvested in northern Germany and sold in Europe at a price of $€$ 5-8 per kg (Woke 2012). Additionally, it is also seen as a new source of crab for the expanding Chinese market, where the value of sold crabs was estimated as high as $€ 3-4.5 \mathrm{~m}$ between 1994 and 2004 (Gollasch 2011). Thus, what at first seemed to be an adverse alien species turned out to be a new profitable ecosystem good.

Generally, it is estimated that over 120 non-native aquatic species are present in the Baltic Sea, about 80 of which have established viable, self-reproducing populations in at least parts of the region (Battle 2009). However, documented data on environmental impacts is available for only 33 , and just 4 species have shown strong impacts on native communities and ecosystem functioning (Battle 2009; Olenin et al. 2010). For example, the invasive dinoflagellate Prorocentrum minimum (Pavillard) Schiller was seen to potentially spread and cause significant impacts on plankton communities, habitats and ecosystem functioning (Olenin et al. 2009). One of the most recent examples of bioinvasion in the Baltic Sea was the introduction of a comb jellyfish Mnemiopsis leidyi (Kube et al. 2007), one of the world's top 100 worst IAS due to its predatory success, partly attributable to its effective foraging strategy (Colin et al. 2010). Nonetheless, unlike in the Black Sea, where the introduction of this jellyfish led to the collapse of the whole ecosystem (Kideys 2002), this species does not seem to pose any direct threat to the Baltic Sea fishery (Jaspers et al. 2011). In other words, it has to be stressed that no significant degradation of local ecosystems with adverse socioeconomic consequences has taken place in the Baltic Sea as a result of IAS. For that reason, AS and IAS have received far less attention than other stressors affecting biodiversity in the Baltic Sea. In fact, many stakeholders consider the bioinvasion problem in the region as relatively minor. What is, however, dangerous for the Baltic Sea ecosystem is a possible synergistic effect of multiple environmental pressures and IAS. Consequences of such multiple pressures are unknown and may negatively affect ecosystem services and functions.

\subsection{Uncertainty in Risk Assessment}

The above-mentioned dual nature of AS causes a number of disagreements among stakeholders, as well as uncertainties that are mainly due to the lack of reliable and conclusive scientific data on different aspects of invaders. The absence of information necessary for an adequate risk analysis - required for developing a regional policy instrument of marine governance - is regarded as the main obstacle to effective risk assessment and IAS management in the Baltic Sea (Lemke et al. 2010; 
Leppäkoski and Gollasch 2006). Long-term data, made available on a centralised platform, on potentially invasive species regarding ecology, introduction routes and recent changes in ecosystems, are essential for developing multiple risk scenarios and appropriate management options for the Baltic Sea. Moreover, better knowledge about possible consequences of IAS is of great importance, since such knowledge is essential for developing early warning systems, constructing target IAS lists and undertaking cost-benefit analyses of management options and environmental status assessments (Olenin et al. 2010).

Targeted monitoring programmes for nonindigenous species are limited and often restricted to a few invasive species in selected areas. Consequently, relevant data is collected mostly as a result of incidental recordings of IAS during already ongoing biological monitoring. Since the monitoring objectives of such tasks are different than observations meant specifically for IAS introduction, the skills of the people gathering this data and the data quality cannot be guaranteed. Obtained records often appear to be of low quality and should be supplemented by targeted monitoring in high-risk areas of both invasive nonindigenous and indigenous species (EC 2011). Unless better monitoring is in place, there will be no reliable basis for providing advice to management, which would be a major obstacle for ecosystem management of IAS regulation/management in the Baltic Sea. One example of an international project that aimed at improving the prevention of pollution, including IAS spread, from maritime transport was Baltic Master II, a strategic European Union project for the Baltic Sea region. Some improvements can be seen worldwide in recent assessment-management interactions because new programmes have started to deal with uncertainty via targeted monitoring and surveillance, the gathering of new data (e.g. on the biology and ecology of potentially invasive species), the routes and mechanisms of bioinvasion as well as the identification and monitoring of vulnerable sites/routes. The major focus of this development seems to be facilitating the implementation of global 'mitigating' regulations such as the International Convention for the Control and Management of Ships' Ballast Water and Sediments (the Ballast Water Management Convention; BWMC), ${ }^{4}$ particularly since the lack of data can be seen as a potential problem for such implementation. Environmental governance, the precautionary principle and EAM are responses to scientific uncertainties and sociopolitical controversies. These approaches are held forward as fruitful alternatives to executive risk-based and sector-restricted regulation, as discussed later in this chapter. However, in the Baltic Sea, IAS is still not regarded as an

\footnotetext{
${ }^{4}$ The BWM Convention (BWMC 2004) is a voluntary agreement of the International Maritime Organisation (IMO), the latter belonging to the family of UN organisations and shipping industry (in particular, the International Chamber of Shipping, the International Association of Independent Tanker Owners and classification societies), to directly address the main vector of alien species introduction. The convention gives specific guidelines regarding risk assessment and management plans. BMWC will be brought into operation in the near future (HELCOM 2013), namely, when at least 30 countries with $35 \%$ of the registered tonnage of the world merchant fleet have ratified the convention. See: http://www.imo.org/About/Conventions/ListOfConventions/Pages/InternationalConvention-for-the-Control-and-Management-of-Ships\%27-Ballast-Water-and-Sediments\%28BWM\%29.aspx
} 
important and urgent issue as in other marine and freshwater basins (e.g. Caspian and Mediterranean Sea, Great Lakes). Only quite recently have IAS received significant attention within EU policy and governance structures (e.g. Shine et al. 2010).

\subsection{Bioinvasions as a New Domain of Environmental Governance}

Due to the global nature of IAS and the increasing number of vectors of transportation, unilateral action by a single stakeholder (e.g. one nation state), even if aligned with the precautionary principle, is usually insufficient to prevent introductions of AS in marine ecosystems (Shine et al. 2010). Moreover, IAS-related environmental risks do not respond to management measures in the same way as other forms of environmental threats. While, for example, existing threats from chemical pollution and eutrophication can be to some extent decreased if appropriate actions are taken, the risk of biological invasion in marine ecosystems can be reduced only by adopting precautionary measures, since control or eradication of once established species is generally regarded as impossible (EC 2011). Genovesi (2007) has given examples of partially successful cases of control and eradication of IAS from marine waters, but so far none have been recorded in Europe (Genovesi 2005). Hence, preventing the introduction of AS is believed to be the best and most cost-effective option (Olenin et al. 2010).

Horizontal (between different stakeholders and sectors) and vertical (international, regional and local) cooperations are essential for developing effective approaches to address crosscutting issues like IAS. Many national and international management instruments and technical guidelines already deal with this problem, focusing on plant and animal health, biodiversity conservation, aquatic/marine ecosystems and maritime transportation (Lemke et al. 2010). These instruments can be binding (e.g. EU regulations) or more voluntary in nature (e.g. HELCOM recommendations) and provide the baseline from which countries and regional organisations such as the European Union develop policies and legal frameworks designed to decrease IAS threats.

Globally, the problem of IAS is addressed in two conventions, namely, the CBD (1992) 5 and the BWMC (2004). In October 2010, the parties to the CBD agreed the following under the CBD Strategic Plan 2011-2020 regarding IAS: 'By 2020, invasive alien species and pathways are identified and prioritised, priority species are controlled or eradicated, and measures are in place to manage pathways to prevent their introduction and establishment' (EC 2011). Additionally, the Global Invasive Species Programme (GISP) established in 1997 provides support for implementing

\footnotetext{
${ }^{5}$ CBD (1992) Article 8(h) requires that, as far as possible, each contracting State should prevent the introduction of, control or eradicate those alien species which threaten ecosystems, habitats or species.
} 
Article 8(h) of CBD and contributes extensively to knowledge and awareness of invasive species through the development of a range of products and publications, including the 'Global Strategy on Invasive Alien Species' and 'Invasive Alien Species: A Toolkit of Best Prevention and Management Practices'.

The importance of ballast waters as a vector through which IAS is transported has been pointed out by many authors. Ship traffic is recognised as the most important vector introducing new organisms into marine ecosystems, especially so in the Baltic Sea (e.g. Carlton and Geller 1993; Carlton 1996; David and Gollasch 2008; Leppakoski et al. 2002; Pikkarainen 2010; Shine et al. 2010). Ship traffic is mainly addressed in regulations and policies dealing with IAS problems in aquatic environments. Before Regulation (EU) No 1143/2014 on invasive alien species ${ }^{6}$ entered into force in January 2015, there had been no consistent and binding legal act or other comprehensive instrument to solve the marine IAS problem in the European Union. However, it should be said that other existing EU legislation and policies do provide some, albeit partial, solutions. ${ }^{7}$ Descriptor 2 of Annex I to the EU Marine Strategy Framework Directive (MSFD) among others specifies that by 2020 'nonindigenous species introduced by human activities are at levels that do not adversely alter the ecosystems' (EC 2011). Here, the objective is to keep IAS populations at a level that does not disturb the ecosystem. However, due to the lack of knowledge, it is often impossible to know when exactly a particular species will significantly alter the ecosystem structure and function.

The EU Communication on 'Our life insurance, our natural capital: an EU biodiversity strategy to 2020' (COM(2011)244), ${ }^{8}$ tabled by the European Commission in 2011, and then followed up by a resolution on the EU 2020 Biodiversity Strategy adopted by the European Parliament in 2012, set a specific target to address the issue of IAS and proposed the preparation of a dedicated legislative instrument to tackle the problem (EU Biodiversity Strategy to 2020). In September 2013, a new proposal for a regulation on the prevention and management of IAS was issued by the European Commission. ${ }^{9}$ This proposal aimed at solving the problem by establishing a framework for action to prevent, minimise and mitigate the negative effects of IAS on biodiversity and ecosystem services. The document underlined the need for coordinated action and prepared a list of species of special concern to the European Union. It also put forward the need for increasing preventive measures

\footnotetext{
${ }^{6}$ Regulation (EU) No 1143/2014 of the European Parliament and of the Council of 22 October 2014 on the prevention and management of the introduction and spread of invasive alien species. http://eur-lex.europa.eu/legal-content/EN/TXT/PDF/?uri=CELEX:32014R1143\&from=EN

${ }^{7}$ Among others: Treaty on the Functioning of the European Union (TFEU - Lisbon Treaty), Sixth Environmental Action Programme (2001-2010), Decision 1600/2002/EC, Council Regulation No 1198/2006 on the European Fisheries Found (OJ L 223, 15.08.2006), Marine Strategy Framework Directive 2008/56/EC (MSFD), Council Regulation No 708/2007 concerning use of alien and locally absent species in aquaculture (OJ L 168 of 28.06.07).

${ }^{8}$ Communication from the commission to the European Parliament, the council, the economic and social committee and the committee of the regions (COM 2011) http://ec.europa.eu/environment/ nature/biodiversity/comm2006/pdf/2020/1_EN_ACT_part1_v7\%5B1\%5D.pdf

${ }^{9} \mathrm{http} / / /$ eur-lex.europa.eu/legal-content/EN/TXT/PDF/?uri=CELEX:52013PC0620\&from=EN
} 
and efficiency, as well as lowering the costs of both damage and undertaken actions (COM/2013/0620final).

The Committee on Fisheries (2013) and the Committee on International Trade (2013) of the European Parliament formulated their opinions on the proposal. The former Committee concentrated on matters that were of relevance to the marine environment or aquaculture. A proposed amendment, among others, was with regard to the list of invasive species of importance to the EU. It was felt that such a list should be kept open and regularly revised and that it should take into account that there are invasive species native to some European regions but alien to others. In other words, the required course of action might differ between Member States (MS). Moreover, it was felt that the public should be kept informed and that a scientific advisory group should be established since scientific advice is seen as a 'key to the successful implementation and oversight of the proposed legislation' (Lemke et al. 2010). Opinions were taken into consideration by the Committee on the Environment, Public Health and Food Safety (2013) and included in the amendments laid down in its draft report on the proposed EC legislation mentioned above.

Finally, the Council adopted a new regulation on IAS and published it in the Official Journal of the European Union on 4 November 2014. ${ }^{10}$ The new regulation entered into force on 1 January 2015 with its main objectives being to "prevent, minimise and mitigate the adverse effects of invasive alien species on biodiversity and related ecosystem services, and on human health and safety as well as to reduce their social and economic impact'. ${ }^{11}$ The IAS problem was to be addressed in a comprehensive way through three main types of interventions, i.e. prevention, early detection and rapid eradication. It was also stated that IAS that were already widely spread needed to be managed.

Nevertheless, at present there are a few mechanisms to support synchronisation of approaches between neighbouring countries or countries in the Baltic subregion, including Russia. Moreover, so far there is no common EU ballast water policy. It seems that the EU is leaning towards ratifying and implementing the BWM Convention. According to the 2013 Proposal (2013/0307COD), Member States that identified ballast waters as an important pathway would have to include in their action plans measures of the BWMC (Article 11 of the proposal). However, Member States are not obliged to ratify the Convention by the new EU regulation, as it is stated in the document: 'Action should build on the experience gained in the Union and in Member States in managing certain pathways, including measures established through the International Convention for the Control and Management of Ships Ballast Water and Sediments adopted in 2004. Accordingly, the Commission should take all appropriate steps to encourage Member States to ratify that Convention'. ${ }^{12}$ Moreover, it was stressed by the Committee on Fisheries in its draft note that although ballast water and hull fouling are the most significant vectors of AS introduction, only five Member States have ratified the BWMC. The Committee

\footnotetext{
${ }^{10} \mathrm{http}: / /$ ec.europa.eu/environment/nature/invasivealien/index_en.htm

${ }^{11} \mathrm{http} / / /$ eur-lex.europa.eu/legal-content/EN/TXT/PDF/?uri=CELEX:32014R1143\&from=EN

${ }^{12} \mathrm{http}: / /$ eur-lex.europa.eu/legal-content/EN/TXT/PDF/?uri=CELEX:32014R1143\&from=EN
} 
suggested that the EU Parliament should persuade all the coastal Member States to endorse the Convention, or even that the EU Commission should consider legislative action in this field. Since Member States differ in their perception of IAS, the framework should be developed with the aim of establishing common objectives, terminology and procedures to prevent bioinvasions in the marine environment, as well as controlling measures for sustaining or restoring marine biodiversity.

In the Baltic Sea region, national legislations and policies relating to IAS risk assessment and management are being developed. Risk analysis is one of the most important activities that are necessary to plan appropriate, science-based and costeffective management options. Risk assessment is a logical process for assessing the likelihood and consequences of specific events, such as the entry, establishment, or spread of harmful aquatic organisms and pathogens. Risk assessment can be qualitative or quantitative, and can be a valuable decision aid if completed in a systemic and rigorous manner (MEPC. 162(56)). ${ }^{13}$ Marine biosecurity risk assessments follow standardised risk procedures and in case of IAS have been previously based on frameworks and concepts of general ecological risk assessment (Leppäkoski and Gollasch 2006). HELCOM's recommendations and the BWM Convention are the most important frameworks for regulating IAS. Although neither of them are legally enforceable, they constitute a significant platform for dialogue on objectives, strategies and measures among all Baltic countries (Fig. 4.3). The BWMC's and IMO's Marine Environment Protection Committee guidelines are regarded as the most important reference documents regarding key principles defining the nature and performance of IAS risk assessment. However, due to the specific ecological and hydrological characteristics of the Baltic Sea, such as its relatively small size, shallow depth and brackish waters, not all of the management options proposed by IMO could be put into practice in the Baltic Sea (Gollasch and Leppäkoski 2007).

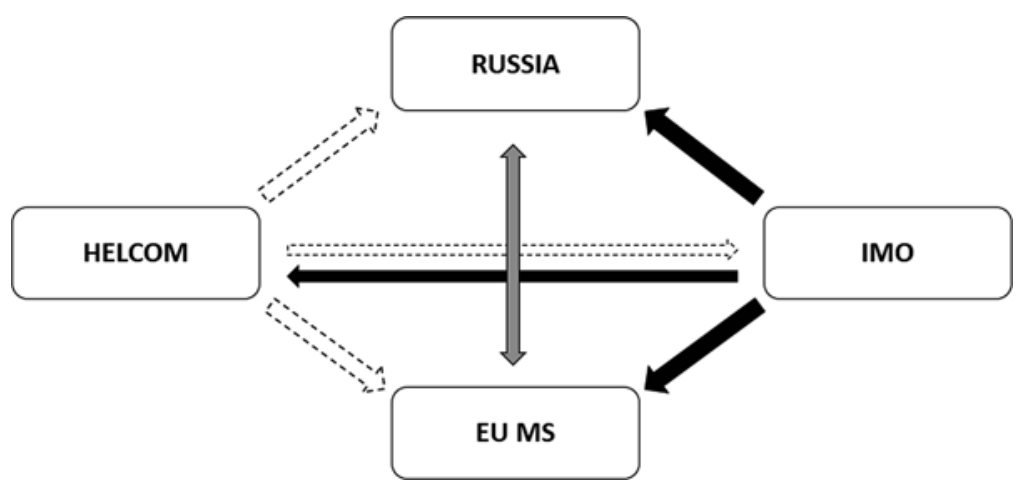

Fig. 4.3 Interactions and ways of communication between main actors involved in IAS decisionmaking in the Baltic Sea region. Arrows: black, BWMC; striped, recommendations for BWMC ratification and acting according to the Baltic Sea Action Plan (BSAP); grey, tension due to different IAS perceptions and priorities occurring within and between riparian states

\footnotetext{
${ }^{13} \mathrm{http}: / /$ www.imo.org/blast/blastDataHelper.asp?data_id=19689\&filename=162\%2856\%29.pdf
} 
For example, there are no specific procedures to assess risks within - instead of between - biogeographic regions proposed in the IMO Guidelines G7. For that reason, strategies to handle the interregional spread of IAS populations and effective methods to carry out surveys within the Baltic Sea were developed by HELCOM. In October 2013, guidelines for the contracting parties of OSPAR and HELCOM on the granting of exemptions under the BWM Convention, regulation A-4, were adopted by the 2013 HELCOM Ministerial Meeting. This document was jointly developed by the Helsinki and OSPAR conventions, in accordance with Art. 13 (3) of the BWMC, to provide a harmonised procedure for the issue of exemptions from Regulation B-3 (Ballast Water Management for Ships) and Regulation C-1 (Additional Measures) under Regulation A-4 and 'to ensure that exemptions are granted in a constant manner that prevents damage to the environment, human health, property or resources' (HELCOM 2013).

Two recent HELCOM projects have also developed guidelines relating to implementation of IAS regulations and management. The first one aimed at giving the contracting parties the option to test, develop and implement the proposed, harmonised system for granting exemptions. ${ }^{14}$ The second one, which was approved by the European Union, studied the harmonisation of the BWM Convention and Marine Strategy Framework Directive monitoring needs on alien species. ${ }^{15}$ One of the most relevant outcomes of HELCOM's actions on IAS risks was the development of the Baltic Sea Regional Project (BSRP) which aimed at creating conditions for applying an ecosystem approach to manage the Baltic Sea and sustain its biological productivity. This is regarded as a basis for developing subsequent programmes and management strategies focused on improving the status of the Baltic Sea environment (Thulin 2009).

According to the BWM Convention, all ships have to have ballast water cleaning systems in order to utilise ballast waters. This precondition has to be fulfilled within $2015-2016,{ }^{16}$ by which time the required number of countries is expected to have ratified the Convention. While all countries that have ratified the Convention have to implement it within 12 months, most countries are yet to work on their implementation plans. If a country has ratified the BWM Convention, it needs to ensure that all ports in the country are prepared for BWM provisions. A detailed implementation plan is needed that will address issues such as (1) ballast water- and sediment-mediated bioinvasion risk assessment, (2) ballast water receiving infrastructure in the donor areas and ballast water treatment systems on ships, (3) uncertainties regarding investment needs and costs and (4) definition of responsibilities.

As Lemke et al. (2010) and Kern (2011) argue, the development of law and its implementation strictly depend on the policies of individual states in the Baltic Sea region (BSR). It is believed that EU's centralised structure and the weak political initiatives of some states (particularly new EU members) stand in the way of

\footnotetext{
${ }^{14} \mathrm{http}: / /$ helcom.fi/helcom-at-work/projects/completed-projects/aliens-3

${ }^{15} \mathrm{http}: / /$ helcom.fi/helcom-at-work/projects/balsam/

${ }^{16}$ The status of the BWMC can be checked at: http://www.imo.org/About/Conventions/ StatusOfConventions/Pages/Default.aspx
} 
developing a regional IAS approach focused on the entire Baltic Sea region. Moreover, governing the Baltic Sea region depends not only on decisions made by national governments of EU Member States but also on EU-Russia agreements and Russia's bilateral relations with individual EU Member States (Kern 2011). Furthermore, Russia is expected to increase marine transportation from and to St. Petersburg, and the lack of binding agreements obliging Russia to act in accordance with the available recommendations can hamper valuable IAS-related initiatives on a Baltic Sea regional scale.

Apart from the BWM Convention, there are a number of voluntary IAS initiatives on various levels. At the international level, there are the pan-European International Council for the Exploration of the Sea, Code of Practice on the Introductions and Transfers of Marine Organisms and the Council of Europe (Bern Convention). There are also country-based individual voluntary engagements that have pathway codes not covered by existing regulatory frameworks for the Baltic Sea area. Although all the mentioned documents and actions constitute valuable and useful rules, compliance is voluntary and does not impose executive measures. At the same time, although shipping was seen as the main vector of IAS several decades ago, public awareness has been raised only recently. Public debates and campaigns have been aimed at eliciting pro-environmental behaviour and encourage voluntary actions among different stakeholders. Voluntary measures can play multiple roles: raise awareness, create social pressure, develop technological innovations, leverage/disseminate best practices, accelerate regime changes or fill regulatory gaps (Harrison 2001). Bussière and Fratzsher (2008) say that 'for a given degree of risk aversion, there is a unique combination of the forecast horizon and of the probability threshold that maximises the policy maker's preferences, yielding the best possible model from a policy perspective'. The outcome of a political process could therefore be a 'continuous improvement process' policy, which aims at compromising the interests of different stakeholder groups, whereas sustainability goals in terms of meeting economic viability and preserving ecosystem goods and services are often not achieved. Nevertheless, due to constant changes in policy objectives, actual measures taken are a patchwork of attempts to cope with change and complexity.

\subsection{Framing and Implementation of the Ecosystem Approach to Management (EAM)}

As a consequence of the increasing use of marine resources, concerns about the health of the seas surrounded by large human populations are growing. Thus, farreaching initiatives to control human activities are being developed. For sustainable management of the marine environment through various management strategies, for example, a maritime security strategy, policy development must address socioeconomic and environmental aspects. However, there is a trade-off between short-term 
profit and long-term sustainability, and it seems that some of the key stakeholders and management agencies often tend to be interested in the former while others, such as numerous environmental agencies, the latter. Christensen et al. (1996) have listed a number of obstacles contributing to the imbalance between short-term solutions and long-term intergenerational sustainability. These include (1) inadequate available information and scarce knowledge about ecosystem structure and functions, (2) centralisation of management and (3) public perception that social and economic arguments outweigh ecological ones. Thus, ecosystem management and EAM itself were seen to be 'silver bullet' solutions to overcome these obstacles. Yet almost two decades later, despite a focus on EAM, these obstacles still remain. As stated earlier, EAM today is acclaimed worldwide not only in science but also in politics as a means of integrating social, economic and ecological objectives. Consequently, the approach is believed to facilitate sustainable development of marine and coastal areas (e.g. Backer et al. 2010; CBD 2002; Curtin and Prellezo 2010). According to Farmer et al. (2012), one of the most important steps in EAM is the development of conceptual models that capture a wide range of people's perceptions about how the system works. The DPSIR (Drivers, Pressures, State change, Impact and Response) approach has been proposed as a modelling approach aimed at shaping environmental sustainability (Atkins et al. 2011; Elliott 2002, 2003). If one examines IAS from a DPSIR perspective, it becomes clear that Drivers facilitating IAS spread in the Baltic Sea include significant environmental risks such as maritime transportation, eutrophication, overfishing and low biodiversity. The Pressures emanating from increased navigation, ballast water discharge, fouling and aquaculture have the potential to change the status of the biological system (IAS interactions with native species). As a consequence, IAS may have impacts at different levels of the ecosystem (native species, biodiversity change) and affect goods and services of interest to mankind (fish stocks, tourism, water quality, health issues). In turn, such a State change needs a Response at the socioeconomic, technological, administrative and legislative levels. It requires controlling the onset of IAS or at a later stage eradicating an already established IAS, with the latter not being feasible in marine environments. Importantly, a precautionary approach appears to dictate the priorities of a top-down approach to controlling IAS (e.g. through the IMO's ballast water management). However, Shine et al. (2010) argue that the assessment of IAS impacts should generally begin at the local level, in 'hot spots' and 'stepping stone areas'. Those are usually marinas and port basins, or areas of special interest like marine protected areas (MPA). Local assessments can be further integrated into evaluations at the next subregional spatial level (e.g. Gulf of Finland in the Baltic or Adriatic Sea in the Mediterranean) or at the regional sea level (EC 2011).

The EAM approach has already been promoted by the Global Invasive Species Programme (GISP) as an effective management approach against biological invasions (CBD Newsletter, 2009-2007). Such a multi-sector and multi-tiered approach is of particular value in areas where eradication of IAS is not the primary goal. EAM also suggests community involvement in developing management processes and includes recipient ecosystem characteristics. The ecosystem approach as described 
in CBD Decision V/6 was also proposed as an appropriate framework for the assessment of planned action and policies with regard to biodiversity considerations for isolated ecosystems (Genovesi and Shine 2004). Out of 12 principles adopted for the application of EAM, at least 4 are of particular interest when it comes to bioinvasions in marine ecosystems. Those are decentralisation of transboundary management, preservation of native ecosystem structure and function, consideration of the economy of the region and multi-sector involvement in the management of IAS (Shine et al. 2000). However, EAM requires good multidisciplinary knowledge about the area, something that is often not available for many marine areas. Often the best available knowledge is not sufficient to take fully informed decisions. Yet it is used.

One example of a continuous and interactive step-by-step approach towards ecosystem-based management is the global Marine Spatial Planning (MSP) network that has been introduced using key components of EAM (Ehler and Douvere 2009). Nevertheless, despite many attempts to move MSP beyond the conceptual level, there are still difficulties with regard to combining conservation with human activities so that marine resources are used sustainably.

The EAM concept is present in some IAS-related EU policies. An example is NATURA 2000 where EAM is linked to reinforcement of appropriate assessments for NATURA 2000 sites. Moreover, the ecosystem approach is also the flagship concept in the most influential EU document on the marine environment - the Marine Strategy Framework Directive (MSFD) adopted in 2008 (Bojārs 2012). The MSFD seeks a comprehensive approach that would combine effective environmental protection with sustainable use of marine resources, hence addressing the needs of society. The management framework for marine protection under MSFD is encapsulated in the section on Marine Strategies, which 'shall apply an ecosystembased approach to the management of human activities' (ibid.). This provides the legal basis that places EAM at the heart of this new obligation placed on EU Member States to address concerns around marine management. However, the Directive does not fully define the sustainability concept nor provide measurable goals specifying future processes and outcomes required for sustainable development. Moreover, it allows for divergent views on what sustainability encompasses and how it can be made operational (Farmer et al. 2012).

The ecosystem approach is also applied in the HELCOM and OSPAR frameworks. In HELCOM BSAP, alien species constitute a factor influencing biodiversity loss. OSPAR has gone even further by developing strategic goals and specific indicators (HELCOM 2010). Another important framework addressing an ecosystem-based approach to resource management is the above-mentioned Baltic Sea Regional Project (BSRP), prepared in collaboration with HELCOM and the Global Environmental Facility (GEF; HELCOM 2006).

Several challenges connected to the implementation of EAM remain such as varying definitions of the approach, lack of cooperation and stakeholder participation, communication concerns and problems with integrating knowledge-based advice across scientific disciplines (Arkema et al. 2006; Barnes and McFadden 2007). In our case study, the major obstacles with EAM implementation pertained 
to mental obstacles and structural challenges, underfinancing, lack of understanding of ecosystem complexity and dynamics, crosscutting issues and environmental interdependencies and lack of dialogue within and between different stakeholder groups. As a number of authors have argued, too little is being done at the governmental level in terms of justifying scientifically the need for regulatory measures and/or prioritisation of management interventions and, more importantly, in national structures and regional institutions responsible for the implementation of preventive measures (Lemke et al. 2010).

The framing of EAM (with definitions of the concept themselves varying quite substantially) among and within different actor groups dealing with IAS has been polarised. Moreover, the concrete meaning of EAM remains incompletely understood and also implemented in the daily work of many stakeholders (Lemke et al. 2010). Only environmental organisations, scholars and other experts seem to be familiar with the meaning of the concept, but they tend to regard EAM as another way of describing their daily work. The EAM model was also seen to be the only holistic way to influence ongoing crosscutting environmental issues. However, this requires breaking down mental and practical barriers that are present in many sectors of the economy and administration (ibid.).

For many actors, the concept serves as a bridge between science, policy and management and is therefore a useful tool in planning, developing and managing activities addressing societal needs and protecting the marine environment. For some stakeholders, it is also regarded as a 'silver bullet' to solve all Baltic Sea problems, which was perceived of as unrealistic by many environmental agencies. It is also important to note that many interviewed representatives from the shipping industry were unfamiliar with EAM and not convinced after being briefed on the concept (Lemke et al. 2010). These stakeholders tend to believe that EAM represents a multi-scale and multidisciplinary challenge, if not an unachievable utopia, and many stated it was irrelevant to what they actually do. This scepticism might be due to the fact that the concept includes adaptive management, acknowledges gaps in ecosystem knowledge and uncertainties, considers multiple external influences and strives to balance diverse societal objectives, but consequently lacks clear goals and tools to implement it in practice.

Many stakeholders feel that EAM lacks an integrated strategy that considers the heterogeneous characteristics of marine space and resolves conflicts among consumers and the natural environment. The challenge of EAM can, however, be turned into an opportunity to improve the foundation of EAM. For this to happen, risk assessment and risk management will have to undergo significant changes, since a variety of institutions need to adapt to new ways of giving, using and implementing recommendations in their daily operating and decision-making processes in accordance with EAM. 


\subsection{Future European IAS Policy: Conclusions and Recommendations}

Increased awareness and legislative mandates pertaining to sustainable development need to be incorporated in the management approaches of natural resource management agencies. Most approaches that seek to address sustainable development have been criticised for focusing on short-term gain rather than long-term environmental, economic and social profits. As mentioned above, far-reaching environmental pressures, associated with the degradation of resources and loss of ecosystem services in the Baltic Sea due to eutrophication, overfishing, pollution, climate change and IAS, together with increasing maritime transportation, are expected to accelerate the spread of AS in the near future. A number of these environmental pressures will further modify ecological processes in ways that boost the societal and environmental impacts of invasive species (Pyke et al. 2008). IAS is a multifaceted problem characterised by complexities in risk assessment and management strategies. Despite structural complexity, functional connectedness and dynamism of an ecosystem, management options often treat different risks as independent issues, while pressures are addressed in separate policies. In the case of IAS, only combined cross-sectoral action could overcome difficulties related to uncertainties in risk assessment and management. We believe that future marine policies covering IAS should include horizontal and vertical interactions between different environmental pressures and their consequences. Currently, only the IMO BWM Convention covers IAS spread via ballast water exchange. Moreover, this policy responds only to ship-mediated species introduction. Furthermore, it is not ratified yet, is not regarded as robust enough to cover different environmental risks and is not detailed enough to be appropriate for Baltic Sea conditions (as explained in Sect. 4.4). There is a need for regulatory measures addressing both various aspects of invasiveness and associated environmental risks, as well as the specificity of the Baltic Sea ecosystem and the political situation that surrounds it.

We believe that IAS management in the Baltic Sea region is ineffective mostly due to a heterogeneous legislative system. First of all, Baltic Sea countries have international obligations to address IAS, principally according to the CBD and BWM Conventions, which are of a general character. Major concerns for future IAS management within the Baltic Sea region are (1) the plethora of EU Directives (i.e. EU Habitats \& Species Directive, Water Framework and Marine Strategy Framework Directives, Directive 2014/89/EU on Maritime Spatial Planning) each implemented to a lesser or greater degree depending on Member State's policies and (2) the number of statutory and other bodies concerned with implementing EU directives and agreements. Thus, the major challenge for the coming years will be promoting Integrated Coastal Zone Management, linked to and based on existing legal frameworks. An integrated governance approach in the Baltic Sea region is a difficult task given the presence of new European Union members in its southern and eastern parts which are also greatly influenced by the Russian Federation. Certain differences in, for example, the understanding of democracy, awareness of environmental 
issues and approach to citizens' engagement in public debates and NGO activities are observed among these riparian states. Moreover, the economic situation differs widely between the countries in the Baltic Sea region and consequently the impact of their industrial and agricultural sectors on the marine environment. Furthermore, transport policies are caught between demands for improved mobility on the one hand and the concern for environmental protection on the other.

The EU IAS policy must be seen in the context of commitments at global, EU and regional levels. It was suggested that a dedicated IAS directive was the most effective way to provide a flexible framework with minimum standards for IAS action in the EU (Shine et al. 2009). Finally, a new dedicated legislative instrument for IAS management was adopted by the Council and entered into force at the beginning of $2015 .{ }^{17}$

Different Member States have been developing different approaches. The lack of a coherent and coordinated approach has hampered the effectiveness of these initiatives, and hence, IAS-related problems continue to increase. Currently, there is a lot of preparation being done at EU and HELCOM levels to help effectively implement the BWM convention. Some EU regulations together with HELCOM guidelines could be used as examples of coordination and consideration of regional requirements for the implementation of BWMC. EU Member States are obliged to cooperate regionally according to Articles 5 and 6 of the MSFD. Furthermore, they must ensure that marine strategies are coherent and coordinated across marine regions or subregions. A new strategy will be based on planned cooperation at EU and MS levels, and for that purpose, Member States must use, where practical and appropriate, existing regional cooperation structures. They are therefore obliged to follow a common approach to initial assessment, determination of good environmental status, management targets, indicators, monitoring and measures (EC 2011). Regarding shipping, ratification of the BWM Convention is a prerequisite, since it is difficult for the EU to take decisions outside of the IMO framework. One of the advantages of the IMO framework is that it is coherent. It also provides for the control of vessels not registered in the EU, but transiting EU waters (Farmer et al. 2012). The EU's objective is to provide a flexible framework with minimum standards based on the precautionary principle and IAS policy so as to ensure coherence with upcoming instruments and emerging solutions (Shine et al. 2010). Preventive measures are also necessary, as well as taking into account interactions with other environmental risks such as eutrophication and overfishing occurring in the Baltic Sea. Preventive measures are diverse and range from education (e.g. public environmental campaigns, workshops, staff training in the maritime industry) to ballast water exchange regulations. Apart from being addressed within maritime transportation and the BWM Convention, the IAS issue should also be considered in other policies dealing with eutrophication, climate change and overfishing since these threats can undermine the conditions under which current IAS policies are developed (especially those where risk assessment is based on species range and invasion pathways). Before preparing any management strategies, effective policies dealing with

${ }^{17} \mathrm{http}: / /$ ec.europa.eu/environment/nature/invasivealien/index_en.htm 
complexity should consider (1) interrelated and crosscutting environmental issues, (2) dynamics of marine ecosystems and (3) clear goals and incentives to vigorously put into practice a new legislation (Shine et al. 2010).

Adaptive management is a way to improve the management process for IAS. Adaptive management is one of the concepts central to EAM that is also integrated in MSFD. Adaptive management recognises that long-term management decisions based upon conceptual modelling or knowledge of only a limited part of the system are unwise due to scientific uncertainty about related natural systems (Farmer et al. 2012). Thus, scientific knowledge and understanding of the system are necessary to reduce management uncertainties. Similarly, effective cooperation of all key stakeholders in a marine region is crucial to facilitate desired outcomes of adaptive management plans. Long-term goals should be revised periodically as new scientific information becomes available and as social needs change (ibid.). Developing a new European legislation on IAS not only generates problems and challenges but also provides an excellent opportunity to bring together crosscutting inquiries and reconsider interactions between different environmental threats. HELCOM was therefore proposed to be the main driving force in the implementation of EAM in the Baltic Sea marine area, as well as the coordinating platform for the Baltic Sea regional implementation of the Marine Directive in the Baltic Sea (EC 2011).

In summary, we believe that despite increased activity in some IAS sectors, there is room for more action at the governmental level as has been the case, for example, in Australia and New Zealand. As importantly, more action is needed within nationstates and regional institutions, especially those responsible for the implementation of all the proposed preventive measures. Despite a number of actions taken, the impact has been limited and the spread of IAS continues to take place. To move from conceptualising solutions to translating them into practice requires (1) defining proper goals and objectives concentrating on sustainability, (2) intergenerational sustainability through the harmonisation of ecosystem processes and functions with management actions and (3) switching to adaptive management that by definition requires cooperation between different stakeholders. Moreover, as IAS risks are interrelated with other environmental threats (e.g. eutrophication, overfishing and climate change), invasive species considerations should be integrated into other policies. These policies should include information on the relevant linkages and recognise the interactions and synergistic effects. The implementation of the BWM Convention dealing with ship-mediated species introduction is an important step forward, but it needs to enter into force. Second, the Convention is not robust enough to cover different environmental risks. Finally, practically speaking, the Convention is still not detailed enough to be appropriate for the Baltic Sea given its peculiar conditions. For these reasons, an implementation strategy for each country that has ratified the BWM Convention is necessary. These strategies would have to address issues such as (1) uncertainties linked to specificity of the Baltic Sea environment and ballast water removal and (2) amending the distribution of responsibilities between ship owner and harbours (e.g. financial responsibilities, planning and building infrastructure for receiving ballast water). Additionally, there 
is a need to introduce new or reinforce existing mechanisms that support a more ecosystem-based governance system. These should ensure not only systematic collection of basic data and the use of the best scientific advice based on robust data but also the introduction of environmental impact assessment as a precondition for new activities. Policy changes and the involvement of stakeholders are crucial to future policy frameworks in order to prevent unwanted introductions and to cover additional vectors of transportations of marine IAS. Voluntary measures are recommended since they supplement frameworks and regulations. Such measures are especially important because high impact policy ideas often lose effectiveness during the political process. We believe that sharing an understanding of EAM with key stakeholders is an important step towards improved environmental governance. We also argue that, for the Baltic Sea, EAM is the only way forward and a good tool for managing risks such as bioinvasions. EAM, the IMO BWMC and international or regional networks could be a solid foundation for developing an integrated system for marine IAS management in the Baltic Sea region.

Acknowledgements This research was funded by the European Community's Seventh Framework Programme (2007-2013) under grant agreement $n^{\circ} 217246$ made with the joint Baltic Sea research and development programme BONUS, as well as by the Polish Ministry of Science and Higher Education. Thanks to two peer reviewers for valuable comments on an earlier version of the chapter.

Open Access This chapter is distributed under the terms of the Creative Commons AttributionNoncommercial 2.5 License (http://creativecommons.org/licenses/by-nc/2.5/) which permits any noncommercial use, distribution, and reproduction in any medium, provided the original author(s) and source are credited.

The images or other third party material in this chapter are included in the work's Creative Commons license, unless indicated otherwise in the credit line; if such material is not included in the work's Creative Commons license and the respective action is not permitted by statutory regulation, users will need to obtain permission from the license holder to duplicate, adapt or reproduce the material.

\section{References}

Arkema KK, Abramson SC, Dewsbury BM (2006) Marine ecosystem-based management: from characterization to implementation. Front Ecol Environ 4:525-532

Atkins JP, Burdon D, Elliott M, Gregory AJ (2011) Management of the marine environment: integrating ecosystem services and societal benefits with the DPSIR framework in a system approach. Mar Pollut Bull 62:215-226

Backer H, Leppänen JM, Brusendorff AC, Forsius K, Stankiewicz M, Mehtonen J, Pyhälä M, Laamanen M, Paulomäki H, Vlasov N, Haaranen T (2010) HELCOM Baltic Sea Action Plan a regional programme of measures for the marine environment based on the ecosystem approach. Mar Pollut Bull 60:642-649

Barnes C, McFadden KW (2007) Marine ecosystem approaches to management: challenges and lessons in the United States. Mar Policy 32:387-392

Battle J (ed) (2009) Silent invasion: the spread of marine invasive species via ships' ballast water. WWF International, Gland 
Bojārs E (2012) Towards a resilient ecosystem of the Baltic Sea. Legal frame for monitoring, assessment and reporting on the status of marine biodiversity. The brochure produced in the frame of the LIFE+ Nature \& Biodiversity project "Innovative approaches for marine biodiversity monitoring and assessment of conservation status of nature values in the Baltic Sea" (Project acronym -MARMONI)

Bonsdorff E (2006) Zoobenthic diversity-gradients in the Baltic Sea: continuous post-glacial succession in a stressed ecosystem. J Exp Mar Biol Ecol 330:383-391

Born W, Rauschmayer F, Brauer I (2005) Economic evaluation of biological invasions - a survey. Ecol Econ 55:321-336

Bull LS, Courchamp F (2009) Management of interacting invasives: ecosystem approaches. In: Clout MN, Williams PA (eds) Invasive species management: a handbook of principles and techniques. Oxford University Press, Oxford, pp 232-247

Bussière M, Fratzscher M (2008) Low probability, high impact: policy making and extreme events. J Policy Model 30:111-121

Carlton J (1996) Pattern, process, and prediction in marine invasion ecology. Biol Conserv 78:97-106

Carlton J, Geller J (1993) Ecological roulette: the global transport of nonindigenous marine organisms. Science 26:78-82

CBD (Convention on Biological Diversity) (2002) Guiding principles for the prevention, introduction and mitigation of impacts of alien invasive species that threaten ecosystems, habitats or species annexed to Decision VI/23. The Hague, April 2002

Christensen M, Norman L, Bartuska AM, Brown JH, Carpenter S, D'Antonio C, Francis R, Franklin JF, MacMahon JA, Noss RF, Parsons DJ, Peterson CH, Turner MG, Woodmansee RG (1996) The report of the Ecological Society of America Committee on the scientific basis for ecosystem management. Ecol Appl 6:665-691

Colin S, Costello J, Hansson L, Titelman J, Dabiri J (2010) Stealth predation and the predatory success of the invasive ctenophore Mnemiopsis leidyi. Proc Natl Acad Sci U S A 107:17223-17227

Committee on Fisheries (2013) Draft opinion of the Committee on Fisheries for the Committee on the Environment, Public Health and Food Safety on the proposal for a regulation of the European Parliament and of the Council on the prevention and management of the introduction and spread of invasive alien species (COM (2013)0620-C7-0264/2013- 2013/307(COD)

Committee on International Trade (2013) Draft opinion of the Committee on Committee on International Trade for the Committee on the Environment, Public Health and Food Safety on the proposal for a regulation of the European Parliament and of the Council on the prevention and management of the introduction and spread of invasive alien species (COM(2013)0620-C7-0264/2013- 2013/307(COD)

Committee on the Environment, Public Health and Food Safety (2013) Draft report on the proposal for a regulation of the European Parliament and of the Council on the prevention and management of the introduction and spread of invasive alien species (COM(2013)0620-C7-0264/2013- 2013/307(COD)

Convention on the protection of the marine environment of the Baltic Sea area (Helsinki Convention), Ospar Convention for the protection of the marine environment of the north-east Atlantic, First joint ministerial meeting of the Helsinki and Ospar commissions (jmm), Bremen: 25-26 June 2003: Statement on the ecosystem approach to the management of human activities "Towards an ecosystem approach to the management of human activities". Accessed 14 June 2012

Curtin R, Prellezo R (2010) Understanding marine ecosystem based management: a literature review. Mar Policy 34:821-830

David M, Gollasch S (2008) EU shipping in the dawn of managing the ballast water issue. Mar Pollut Bull 56:1966-1972

Didžiulis V (2006) NOBANIS - Invasive alien species fact sheet - Marenzelleria neglecta. Online Database of the North European and Baltic Network on Invasive Alien Species NOBANIS. Available from: www.nobanis.org. Accessed 20 Aug 2012 
EC (European Commission) (2011) Working paper. Relationship between the initial assessment of marine waters and the criteria for good environmental status

Ehler Ch, Douvere F (2009) Marine spatial planning: a step-by-step approach toward ecosystembased management. Intergovernmental Oceanographic Commission and Man and the Biosphere Programme. IOC Manual and Guides No. 53, ICAM Dossier No. 6. UNESCO, Paris

Elliot M (2002) The role of the DPSIR approach and conceptual models in marine environmental management: an example for offshore wind power. Mar Pollut Bull 44:iii-vii

Elliot M (2003) Biological pollutants and biological pollution - an increasing cause for concern. Mar Pollut Bull 46:275-280

EU Biodiversity Strategy to 2020 - towards implementation. Available from: http://ec.europa.eu/ environment/nature/biodiversity/comm2006/2020.htm. Accessed 23 Aug 2012

Farmer A, Mee L, Langmead O, Cooper P, Kannen A, Kershaw P, Cherrier V (2012) The ecosystem approach in marine management. EU FP7 KNOWSEAS Project

Genovesi P (2005) Eradications of invasive alien species in Europe: a review. Biol Invasions 7:127-133

Genovesi P (2007) Limits and potentialities of eradication as a tool for addressing biological invasions. In: Caldwell MM, Heldmaier G, Jackson RB, Lange OL Mooney HA, Schulze ED, Sommer U (eds) Biological invasions, Ecological studies vol 193, pp 385-403

Genovesi P Shine C (2004) European strategy on invasive alien species. Convention on the conservation of European Wildlife and habitats (Bern Convention) Nature and environment, no. 137

Gollasch S (2011) NOBANIS - invasive alien species fact sheet - Eriocheir sinensis. Available from: Online Database of the European Network on Invasive Alien Species www.nobanis.org. Accessed 22 Jan 2013

Gollasch S, Leppäkoski E (2007) Risk assessment and management scenarios for ballast water mediated species introductions into the Baltic Sea. Aquat Invasions 4:313-340

Harrison K (2001) Voluntarism and environmental governance. In: Parson E (ed) Governing the environment: persistent challenges, uncertain innovations. University of Toronto Press, Toronto

HELCOM (2006) Report of the second HELCOM/BSRP thematic workshop on the risk related to the ballast water mediated introductions of non-indigenous species in the Baltic Sea

HELCOM (2009a) Overview of the shipping traffic in the Baltic Sea. Available from: www.helcom.fi/stc/files/shipping/Overview\%20of\%20ships\%20traffic_updateApril2009.pdf. Accessed May 2010

HELCOM (2009b) HELCOM activities related to the transfer of alien species in the Baltic Sea. Available from: www.unep.org/regionalseas/globalmeetings/11/inf.08-alien-speciesHELCOM.pdf. Accessed Sept 2010

HELCOM (2009c) Biodiversity in the Baltic Sea - An integrated thematic assessment on biodiversity and nature conservation in the Baltic Sea. Balt. Sea Environ. Proc. No. 116B. Available from: http://helcom.fi/Lists/Publications/BSEP116B.pdf\#search=ship\%20traffic\%20stat. Accessed June 2014

HELCOM (2010) Road map towards harmonized implementation. Available from: www.helcom. fi/BSAP/ActionPlan/otherDocs/en_GB/roadmap/. Accessed May 2010

HELCOM (2013) Joint HELCOM/Ospar guidelines on the granting of exemptions under the International Convention for the Control and Management of Ships' Ballast Water and Sediments, Regulation A-4

Jaspers C, Titelman J, Nansson LJ, Haraldsson M, Ditlefsen CR (2011) The invasive ctenophore Mnemiopsis leidyi poses no threat to Baltic cod eggs and larvae. Limnol Oceanogr 56:431-439

Kern K (2011) Governance for sustainable development in the Baltic Sea region. J Balt Stud 421:21-35

Kideys AE (2002) Fall and rise of the Black Sea ecosystem. Science 297:1482-1484 
Kotta J, Olafsson E (2003) Competition for food between the introduced polychaete Marenzelleria viridis (Verrill) and the native amphipod Monoporeia affinis Lindström in the Baltic Sea. J Sea Res 50:27-35

Kotta J, Kotta I, Simm M, Lankov A, Lauringson V, Põllumäe A, Ojaveer H (2006) Ecological consequences of biological invasions: three invertebrate case studies in the north-eastern Baltic Sea. Helgol Mar Res 60:106-112

Kube S, Lutz P, Honnef C, Augustin CB (2007) Mnemiopsis leidyi in the Baltic Sea - distribution and overwintering between autumn 2006 and spring 2007. Aquat Invasions 2:137-145

Lemke P, Smolarz K, Zgrundo A, Wolowicz M (2010) Biodiversity with regard to alien species in the Baltic Sea region. RISKGOV report to BONUS EEIG Programme; University of Gdansk, Institute of Oceanography, Gdynia. Available from: http://www.sh.se/riskgov

Leppäkoski E, Gollasch S (2006) Risk assessment of ballast water mediated species introductions - A Baltic Sea approach. HELCOM report. Available from: www.helcom.fi/stc/files/shipping/Ballast\%20Water\%20Mediated\%20Species\%20Introductions.pdf. Accessed June 2010

Leppäkoski E, Gollasch S, Olenin S (eds) (2002) Invasive aquatic species of Europe - distribution, impact and management. Kluwer Academic Publishers, Dordrecht

Mare DG (2012). Blue growth. Scenarios and drivers for sustainable growth from the oceans, seas and coasts. Third Interim Report

Olenin I, Hajdu S, Wasmund N, Jurgensome I, Gromisz S, Kownacka J, Toming K, Olenin S (2009) Impacts of invasive phytoplankton species on the Baltic Sea ecosystem in 1980-2008. HELCOM Baltic Sea Environmental Fact Sheet, Available from http://helcom.fi/baltic-seatrends/environment-fact-sheets. Accessed June 2009

Olenin S, Alemany F, Cardoso AC, Gollasch S, Goulletquer P, Lehtiniemi M, McCollin T, Minchin D, Miossec L, Occhipinti Ambrogi A, Ojaveer H, Rose JK, Stankiewicz M, Wallentinus I, Aleksandrov B (2010) Marine Strategy Framework Directive, Task Group 2 report, non-indigenous species. Office for Official Publications of the European Communities, Luxembourg

Pikkarainen A (2010) Maritime traffic and alien species introductions in the Baltic Sea. Available from: www.merikotka.fi/tiedotteet/Pikkarainen_2010_Alien_species_final2. Accessed Sept 2010

Pyke CR, Thomas R, Porter RD, Hellmann JJ, Dukes JS, Lodge DM, Chavarria G (2008) Current practices and future opportunities for policy on climate change and invasive species. Conserv Biol 22(3):585-592

Shine C, Williams N, Gündling L (2000) A Guide to designing legal and institutional frameworks on alien invasive species. IUCN, Gland

Shine C, Kettunen M, ten Brink P, Genovesi P, Gollasch S (2009) Technical support to EU strategy on invasive species (IAS) - recommendations on policy options to control the negative impacts of IAS on biodiversity in Europe and the EU. Final report for the European Commission. Institute for European Environmental Policy (IEEP), Brussels

Shine C, Kettunen M, Genovesi P, Essl F, Gollasch S, Rabitsch W, Scalera R, Starfinger U, ten Brink P (2010) Assessment to support continued development of the EU Strategy to combat invasive alien species. Final report for the European Commission. Institute for European Environmental Policy (IEEP), Brussels

Thulin J (2009) The recovery and sustainability of the Baltic Sea large marine ecosystem. In: Sherman K, Aquarone MC, Adams S (eds) Sustaining the world's large marine ecosystems. IUCN, Gland, pp 63-75

Woke L (2012) Europe's unwanted guest savoured in China. China Daily 2012-10-15. Available from: http://www.chinadaily.com.cn/cndy/2012-10/15/content_15816422.htm. Accessed 22 Jan 2013

Zavaleta ES, Hobbs RJ, Mooney HA (2001) Viewing invasive species removal in a wholeecosystem context. Trends Ecol Evol 16:454-459 